\title{
The Downward Spiral of Chronic Pain, Prescription Opioid Misuse, and Addiction: Cognitive, Affective, and Neuropsychopharmacologic Pathways
}

\author{
Eric L. Garland, Ph.D. ${ }^{1}$, Brett Froeliger, Ph.D. ${ }^{2}$, Fadel Zeidan, Ph.D. ${ }^{3}$, Kaitlyn Partin, M.S.W. \\ 4 , and Matthew O. Howard, Ph.D. ${ }^{5}$ \\ ${ }^{1}$ Huntsman Cancer Institute, University of Utah. \\ 2 Department of Neuroscience, Medical University of South Carolina. \\ ${ }^{3}$ Department of Neurobiology and Anatomy, Wake Forest University. \\ ${ }^{4}$ Fort Walton Beach Medical Center. University of North Carolina at Chapel Hill. \\ ${ }^{5}$ School of Social Work, University of North Carolina at Chapel Hill.
}

\begin{abstract}
Prescription opioid misuse and addiction among chronic pain patients are emerging public health concerns of considerable significance. Estimates suggest that more than $10 \%$ of chronic pain patients misuse opioid analgesics, and the number of fatalities related to nonmedical or inappropriate use of prescription opioids is climbing. Because the prevalence and adverse consequences of this threat are increasing, there is a pressing need for research that identifies the biobehavioral risk chain linking chronic pain, opioid analgesia, and addictive behaviors. To that end, the current manuscript draws upon current neuropsychopharmacologic research to provide a conceptual framework of the downward spiral leading to prescription opioid misuse and addiction among chronic pain patients receiving opioid analgesic pharmacotherapy. Addictive use of opioids is described as the outcome of a cycle initiated by chronic pain and negative affect and reinforced by opioidergic-dopamingeric interactions, leading to attentional hypervigilance for pain and drug cues, dysfunctional connectivity between self-referential and cognitive control networks in the brain, and allostatic dysregulation of stress and reward circuitry. Implications for clinical practice are discussed; multimodal, mindfulness-oriented treatment is introduced as a potentially effective approach to disrupting the downward spiral and facilitating recovery from chronic pain and opioid addiction.
\end{abstract}

\section{Keywords}

chronic pain; opioid misuse; addiction; allostasis; reward; attentional bias; default mode; mindfulness

(C) 2013 Elsevier Ltd. All rights reserved

Corresponding author. Eric L. Garland, 395 South, 1500 East, Salt Lake City, UT, 84112, elgarlan@ gmail.com, 919-943-6022.

Publisher's Disclaimer: This is a PDF file of an unedited manuscript that has been accepted for publication. As a service to our customers we are providing this early version of the manuscript. The manuscript will undergo copyediting, typesetting, and review of the resulting proof before it is published in its final citable form. Please note that during the production process errors may be discovered which could affect the content, and all legal disclaimers that apply to the journal pertain. 


\section{Introduction}

\subsection{The scope of chronic pain and prescription opioid misuse}

Misuse of prescription opioid analgesics is an emerging public health concern that confers significant risks for overdose, unsafe drug interactions, and the full panoply of adverse social, legal, and adaptive consequences associated with dependence on any psychoactive drug. Though the prevalence of prescription opioid misuse across the general U.S.

population has increased more than threefold over the past two decades (Hall et al., 2008), it is presently unclear to what extent this explosion in prevalence reflects an increase in opioid misuse by persons without a prescription for opioids versus an increase in nonmedical use of opioids by persons prescribed opioids for analgesia. This distinction notwithstanding, nationally-representative surveys indicate that prescription opioid misuse is endemic among U.S. adolescents and adults; prescription opioids are now among the most commonly misused drugs in the U.S. (Wilson, 2007). For instance, results of the National Survey on Drug Use and Health (NSDUH) for 18-to-25 year-olds revealed that $23.8 \%, 11.1 \%$, and $4.8 \%$ reported lifetime, past year, and past month misuse of prescription "pain killers" (Substance Abuse and Mental Health Services Administration, 2011). NSDUH findings further indicated that rates of initiation of nonmedical pain reliever use were second only to those of marijuana, with more than two million persons initiating nonmedical use of opioid analgesics annually. These findings underscore the pervasive availability and misuse of these agents in the U.S. The ready accessibility, prevalent misuse, and euphorigenic effects of prescription opioids would seem to create conditions for widespread dependence on these agents (Mendelson, Flower, Pletcher, \& Galloway, 2008). Recent research does, in fact, suggest that rates of publically-funded chemical dependency treatment and emergency department care for prescription opioid use have increased dramatically in recent years and it is estimated that well over a million Americans are currently dependent on prescription opioids (Manubay, Muchow, \& Sullivan, 2011; Mendelson et al., 2008). As previously underscored, these statistics do not clearly differentiate opioid misusers with and without chronic pain; yet, this is a critically important distinction with serious clinical ramifications.

\subsection{Diagnostic classification of opioid use patterns}

The issue of prescription opioid misuse is further complicated by the diversity of nosological categories used to classify opioid use patterns and their biopsychosocial consequences. As defined by Diagnostic and Statistical Manual of Mental Disorders, Fourth Edition (DSMIV), prescription opioid abuse involves a maladaptive pattern of repeated opioid use that: results in failure to fulfill social, occupational, academic, or familial obligations; continues despite recurrent legal problems related to opioid use; persists in spite of interpersonal problems caused or exacerbated by opioids; and occurs in physically hazardous contexts. In contrast, DSM-IV defines prescription opioid dependence as involving physical symptoms of dependence, including tolerance and withdrawal, as well as behavioral symptoms including: taking higher doses than intended; an inability to reduce or stop taking opioids; spending substantial amounts of time using, obtaining, recovering, or thinking about opioids; and continued use in spite of adverse physical or psychological consequences (Zacny et al., 2003). However, some clinicians believe these behavioral criteria for abuse and dependence are inappropriate for opioid-using chronic pain patients, because patients who take opioids as prescribed may be unable to reduce their opioid use or may continue opioid use despite adverse health consequences due to the intractability of their chronic pain. Instead, many pain and addiction specialists use the American Pain Society (2002) criteria to identify prescription opioid addiction among chronic pain patients, including symptoms of impaired control over opioid use, compulsive opioid use, continued use despite harm, and craving for opioids (Sullivan et al., 2008; Wilson, 2007). Addictive tendencies among prescription opioid users may be presaged by the presence of opioid misuse behaviors such 
as selling medication or injecting oral formulas (Ives et al., 2006; Sullivan et al., 2008), although less serious forms of opioid misuse like unauthorized dose escalation are relatively common among undertreated chronic pain patients and may not indicate opioid addiction. The presence of more serious misuse behaviors may mark the transition from sanctioned use of opioids to development of opioid use disorders and addiction (Butler et al., 2007).

\subsection{Epidemiology of prescription opioid misuse}

Parsing apart these conditions, structured psychiatric interviews conducted for the National Epidemiologic Survey on Alcohol and Related Conditions (NESARC) study of more than 43,000 U.S. adults identified $4.7 \%$ of respondents as lifetime prescription opioid misusers; whereas $1.4 \%$ of respondents met criteria for a DSM-IV prescription opioid use disorder (opioid abuse or dependence; Huang et al., 2006). Men, adults with Axis I and Axis II DSMIV diagnoses, respondents residing in the West, and young or middle aged adults were at greatest risk for prescription drug misuse and a prescription opioid use disorder. Other studies have identified a history of alcohol or illicit drug misuse, anxiety, depression, and chronic pain as significant risk factors for prescription opioid misuse and dependence (Amari, Rehm, Goldner, \& Fischer, 2011; Pohl \& Smith, 2012; Turk, Swanson, \& Gatchel, 2008). Individuals suffering from chronic pain disorders, who are at risk for becoming physically dependent on opioid analgesics when adhering to their prescribed medication regimen, may be particularly vulnerable to prescription opioid misuse (Butler et al., 2007; Ives et al., 2006; Sullivan et al., 2010).

Though the prevalence of prescription opioid misuse and addiction among chronic pain patients has yet to be firmly established by nationally-representative, population-level surveys, chronic pain itself is highly prevalent in modern society; a meta-analysis of 13 studies reported a weighted mean prevalence of $35.5 \%$ for chronic pain of any kind and a weighted mean prevalence of $11 \%$ for severe chronic pain (Ospina \& Harstall, 2002). Many patients with chronic pain have serious medical conditions that require long-term opioid pharmacotherapy, and a subset of these individuals are at significant risk for escalating from appropriate opioid use to misuse and finally to opioid addiction. The best available prevalence estimates for opioid misuse and addiction among chronic pain patients may be derived from research by Fishbain and colleagues (2007), who reviewed 67 methodologically rigorous studies including thousands of chronic pain patients and concluded that $3.3 \%, 11.5 \%$, and $14.5 \%$ of these patients, in toto, became addicted to prescription opioids, engaged in opioid misuse behaviors such as unauthorized dose escalation and drug hoarding, and used illicit drugs, respectively. Thus, while prescription opioid addiction among chronic pain patients appears to be relatively rare, opioid misuse in this population is more common. Although relatively few studies have prospectively examined factors related to increased risk for prescription drug misuse among chronic pain patients receiving ongoing opioid pharmacotherapy, recent reports suggest that greater baseline pain intensity (Edwards et al., 2011; Jamison, Link, \& Marceau, 2009), psychological distress and behavioral problems (Jamison, Butler, Budman, Edwards, \& Wasan, 2010), and status as a cigarette smoker (Novy et al., 2012) predict greater risk for transitions to prescription opioid misuse, abuse and addiction. There is a pressing need for additional studies to better understand the risk factors for progression to opioid misuse and opioid use disorders among chronic pain patients receiving prescription opioid pharmacotherapy (Larance, Degenhardt, Lintzeris, Winstock, \& Mattick, 2011). Further, novel conceptual frameworks are needed to delineate the biobehavioral risk chain linking pain, opioid analgesia, opioid misuse, and addiction.

The purpose of this paper is to describe how the neuropharmacologic properties of prescription opioids interact with cognitive, affective, and physiological factors implicated in chronic pain and addictive behavior. We first review the neurobiology of opioid agents 
and pain processing in the human nervous system. Next, we present a conceptual model to describe how chronic pain, affective dysregulation, and opioid use interact to potentiate each other and foster opioid addiction. Lastly, we discuss clinical implications of the model for psychological treatment of chronic pain patients and for the prevention of opioid misuse in these populations.

\section{Neuropharmacologic Effects of Acute Opioid Administration on Central Nervous System Function}

\subsection{Effects of opioids on neurotransmission}

Opioidergic neurotransmission is necessary for the biologic integrity of the human nervous system. Both opioid medication and endogenous opioids (those naturally produced by the body such as beta-endorphin and enkephalins) interact with mu, kappa and delta opioid receptor-proteins on neuronal membranes widely distributed throughout the cerebral cortex, thalamus, hypothalamus, periaqueductal grey, interpeduncular median raphe nuclei, and spinal cord (Arvidsson et al., 1995; Lewis, Pert, Pert, \& Herkenham, 1983; Mathieu-Kia, Fan, Kreek, Simon, \& Hiller, 2001; Pan \& Pasternak, 2011; Traynor \& Wood, 1987). While mu receptor activation mediates the analgesic properties of selective mu opioid agonists like morphine, codeine, heroin, meperidine, methadone, and hydromorphone (Becker, Gandhi, \& Schweinhardt, 2012; Fields, 2011; Julien, 2007), the abuse liability of prescription opiate medications is thought to be due to the interactive effects of mu receptor activation on dopaminergic transmission. Acute administration of mu receptor agonists indirectly excites dopamine-secreting neurons in the ventral tegmental area via GABAergic mechanisms (Chiara \& North, 1992; Johnson \& North, 1992). Indirect action of opioids on dopamine neurotransmission appears to be integral to the reinforcing and rewarding properties of opioids, as well as opioid addiction (Berridge, Robinson, \& Aldridge, 2009; Le Merrer, Becker, Befort, \& Kieffer, 2009; Volkow, Wang, Fowler, Tomasi, \& Telang, 2011).

\subsection{Effects of opioids on neurocognition}

Functional magnetic resonance imaging (fMRI) has provided insight into the effects of opioid administration on human brain function. Single-dose opioid administration to opioidnaïve, healthy individuals activates brain regions involved in processing reward (nucleus accumbens, extended amygdala, orbitalfrontal gyrus, and hippocampus) (Becerra, Harter, Gonzalez, \& Borsook, 2006; Wanigasekera et al., 2012), while decreasing brain activation in brain regions involved in cognitive control and attention (dorsolateral prefrontal cortex, anterior cingulate cortex, inferior parietal lobe) (Becerra et al., 2006; Jastrzab, Mackey, Chu, Stringer, \& Younger, 2012; Lee, Wanigasekera, \& Tracey, 2012). Opioid-induced hyperactivation of limbic circuitry is similar to that elicited by psychostimulants (Breiter et al., 1997), whereas opioid-induced cortical inhibition is comparable to that elicited by sedative or anesthetic drugs (Fiset, Plourde, \& Backman, 2005). Acute administration of higher concentrations of opioids reduces neural activity in the brain stem and medial thalamic nuclei, which can lead to diminished sensory, motor, and cognitive functioning to the point of unconsciousness (Becerra et al., 2006). Other neuroimaging research, involving single-dose opioid administration in the absence of pain to healthy individuals, revealed activations in orbitofrontal cortex, anterior cingulate cortex, insula, and amygdala that were associated with the time course of subjective reports of dizziness, drowsiness, and euphoria (Leppä et al., 2006). Consistent with prevailing models of drug addiction, these findings suggest that high-risk individuals may start along the path of addiction to prescription opioids after experiencing an initial and transient hyperactivation of reward circuitry coupled with disruption in neural circuitry subserving cognitive function. 
Disrupted cognitive control neural circuitry function is evident in a host of studies indicating cognitive and psychomotor impairments such as decrements in working memory, reduced cognitive flexibility, and increased impulsivity in long-term opioid users (Baldacchino, Balfour, Passetti, Humphris, \& Matthews, 2012; Mintzer, Copersino, \& Stitzer, 2005; Prosser, London, \& Galynker, 2009; Verdejo, Toribio, Orozco, Puente, \& Pérez-García, 2005; Zacny, 1995) and healthy, opioid-naïve individuals (Baldacchino, Balfour, Passetti, Humphris, \& Matthews, 2012; Cherrier, Amory, Ersek, Risler, \& Shen, 2009; Schneider et al., 1999; Walker \& Zacny, 1999; Zacny, 1995). Deactivation in brain regions involved in executive function (e.g., anterior cingulate cortex, dorsolateral prefrontal cortex) following acute, single-dose opioid administration provides further mechanistic insight into the relationship between opioid use and cognitive impairment (Becerra et al., 2006; Jastrzab et al., 2012; Lee et al., 2012; Prosser et al., 2009). Opioid-induced deficits in executive function, compounded with those associated with chronic pain (Kendall et al., 2010; Tassain et al., 2003), may compromise the patient's ability to exert cognitive control needed to cope through non-pharmacologic means, thereby inadvertently promoting dependence on opioids as a means of obtaining relief from pain.

\section{Pain and the Nociceptive and Affective Dimensions of Opioid-Induced Analgesia}

\subsection{Neurophysiology of pain}

Pain is a complex, biopsychosocial experience that arises from the interaction between sensory, cognitive, and affective factors. Acute pain is most often induced by noxious stimulation, tissue damage, and/or disease and is a beneficial process that helps to preserve the morphological integrity of the organism. Acute pain is associated with activation in a widely distributed network of highly connected brain regions including primary and secondary somatosensory cortices, bilateral insula, thalamus, anterior cingulate cortex, and the prefrontal cortex (Coghill, McHaffie, \& Yen, 2003). Chronic pain on the other hand may not be clearly linked to an observable physiological or neural pathology. In some cases, the CNS may generate pain in the absence of input from peripheral or visceral nociceptors, as evidenced by conditions like phantom limb pain, irritable bowel syndrome, and chronic pain due to CNS changes secondary to stroke (Loeser \& Melzack, 1999; Melzack, 1999; Spiller et al., 2007). In such cases, the intensity of chronic pain is only weakly or not at all associated with the degree of actual tissue damage (Waddell, McCulloch, Kummel, \& Venner, 1980; Waddell, 1996). With time, pain may become the output of a pattern of familiar sensory inputs triggering cognitive and affective reactions that have previously been tied to the pain experience (Melzack, 1999). In this way, even the anticipation of pain and suffering may result in somatic discomfort or functional disability of a similar or even greater magnitude as the actual painful event (Crombez, Vlaeyen, Heuts, \& Lysens, 1999). Chronic pain may be exacerbated by stress, environmental variables, emotional states, and other psychological factors (Garland, 2012; Loeser \& Melzack, 1999; Voscopoulos \& Lema, 2010).

\subsection{A role for default mode networks in pain processing}

Although in some cases chronic pain stems from an initial painful insult to the body, its progression is associated with the interaction between original injury, CNS, and cognitiveaffective dysregulation (Apkarian, Bushnell, Treede, \& Zubieta, 2005). With regard to the latter factor, recent neuroimaging research has identified a role for self-referential thought processes in chronic pain (Baliki et al., 2006; Loggia et al., 2012; Wasan et al., 2011). In healthy individuals, self-referential thought (i.e., thought pertaining to an individual's autobiographical narrative or life story) is believed to be reflected by oscillating activity in a distinct network of brain regions (posterior cingulate cortex/precuneus, medial prefrontal 
cortex, and the inferior and lateral temporal cortices) referred to as the default mode network (DMN) (Raichle et al., 2001). Recent findings from resting-state functional connectivity analyses of regional brain signals reveal that chronic pain patients exhibit abnormal functional connections between the default mode network and the anterior insula (Loggia et al., 2012), a region crucially involved in evaluating sensory processes. It has been postulated that the experience of chronic pain is related to abnormal default mode processes where pain experience becomes the primary object of self-referential thought (Zeidan \& Coghill, 2012). Dysregulated DMN connectivity may underpin the development of the entrapped sense of identity and autobiographical narrative dominated by pain-related memories and associations so common to chronic pain patients (Hellström, 2001; Morley, Davies, \& Barton, 2005; Pincus \& Morley, 2001). The relationship between DMN and chronic pain is also supported by findings demonstrating the role of the perigenual anterior cingulate cortex, a brain region involved in mediating the cognitive modulation of pain (Vogt, 2005). Recent findings reveal that chronic pain patient's self-report of pain is negatively associated with connectivity between the perigenual anterior cingulate cortex and the DMN (Loggia et al., 2012; Wasan et al., 2011). That is, those who report more intense chronic pain exhibit decreased connectivity between the perigenual anterior cingulate and the DMN, likely reflecting reduced ability to govern pain-related thought processes. Conversely, increased functional connectivity between anterior cingulate and DMN regions may reflect a process for attenuating pain.

\subsection{Descending nociceptive inhibition and opioid analgesia}

Thus, the brain does not passively receive nociceptive information from the body, but instead actively regulates nociception by way of interactions between descending pain modulatory system (Heinricher, Tavares, Leith, \& Lumb, 2009; Melzack \& Wall, 1965; Reynolds, 1969) and cortico-cortical networks (Rainville, 2002). The descending pain modulatory system exerts influences on nociceptive input from the spinal cord through a network of cortical, subcortical, and brainstem structures including prefrontal cortex, anterior cingulate cortex, insula, amygdala, hypothalamus, periaqueductal grey, rostral ventromedial medulla, and dorsolateral pons (Tracey \& Mantyh, 2007). The descending pain modulatory system has been construed as the means by which the CNS inhibits nociceptive signals at the spinal outputs (Heinricher et al., 2009). Endogenous and exogenous opioids relieve pain by targeting the descending pain modulatory system (Besson, 1999), most notably in the periaqueductal grey, a brain region involved in processing the placeboanalgesia (Tracey, 2010). In addition, acute, single-dose administration of opioids in healthy individuals exerts direct analgesic effects by reducing sensory evaluation processes evidenced by reduced activation in brain regions corresponding to processing lower-level afferent processes (i.e., primary and secondary somatosensory cortex, thalamus) (Wagner et al., 2007; Wise et al., 2002), and by modulating neurotransmission in the substantia gelatinosa of the dorsal horn of the spine (Le Bars, Guilbaud, Chitour, \& Besson, 1980; Yaksh, 1981, 1987). Moreover, in a preclinical animal model, acute opioid administration elicited dose-dependent modulation of dopaminergic activity in spinal neurons that mediate nociception (Pappas, Kennedy, Goudreau, \& Lookingland, 2011). Among healthy human volunteers, increasing concentrations of opioids across a single, experimental session monotonically decreased sensory processing in primary and secondary somatosensory cortex and the posterior insula, while dramatically attenuating pain processing in brain regions that mediate affective dimension of pain like the amygdala (Oertel et al., 2007).

Given the complexity of pain, it is perhaps not surprising that opioid analgesia operates through both neuropharmacologic and psychological mechanisms. In addition to attenuating sensory aspects of pain (i.e., nociception), opioids may alleviate the affective dimensions of pain (e.g., suffering). In that regard, among healthy individuals, analgesia induced through 
acute opioid administration operates, in part, through modulating activation of the anterior and posterior cingulate cortex (Wagner et al., 2007), anterior insula (Oertel et al., 2007), and the hypothalamus (Becerra et al., 2006), key nodes in the central autonomic network, a series of neural circuits that regulate attention, emotion, and neurovisceral integration (Thayer \& Lane, 2009). Opioids, like all drugs of addiction, also stimulate mesolimbic dopamine reward systems (Chiara \& North, 1992; Johnson \& North, 1992). Opioid-induced dopamine release in the nucleus accumbens associated with positive mood and reward may confer therapeutic benefit for pain management (Center, 2011). Indeed, pleasure and pain have mutually inhibitory effects through complex opioid-dopamine interactions in corticolimbic-striatal circuitry (Leknes \& Tracey, 2008). Through these and other neural targets, opioids change the attentional and affective response to nociceptive information, and in so doing, temper the emotional averseness and unpleasantness of pain (Dellemijn \& Vanneste, 1997). To be clear, much of what is known about the psychobiological mechanisms of opioid-induced analgesia comes from studies of healthy individuals exposed to laboratory pain inductions. Yet, the development of co-occurring chronic pain and opioid use disorders over time may alter the neurobiological response to opioids in clinically significant ways, as detailed below.

\section{Neurobiological transitions from opioid use to dependence and addiction}

\subsection{The neurobiological progression from opioid use to dependence}

Opioid therapy for chronic pain often provides effective analgesia but confers significant risk for the development of opioid use disorders in a subset of vulnerable individuals (Denisco et al., 2008; Passik, 2009), as described earlier in the introduction of this paper. Prolonged, medically-appropriate opioid use produces physical dependence symptoms via neuroadaptations resulting in tolerance to opioids, withdrawal when opioids are discontinued, and, in some instances, opioid-induced hyperalgesia (Chu, Angst, \& Clark, 2008). These physical symptoms of opioid dependence are natural responses to extended use of opioids, and do not signal the presence of an opioid use disorder. Thus, there is a difference between physiological dependence on opioids and the pathology of addiction (Shurman, Koob, \& Gutstein, 2010). Addiction arises from a usurpation of normal reward learning mechanisms caused by repeated pharmacologic interruption to normal brain function, resulting in neuroadaptations and fundamental alterations to brain structure. Such neuroplastic changes commence with early use of opioids as associations are forged between drug-related stimuli and reward responses (i.e., transient neuroplasticity), and may eventuate in compulsive, addictive habits as these neurobiological changes become entrenched (i.e., stable neuroplasticity) (Kalivas \& O’Brien, 2008).

Opioid-induced durable changes in brain structure and function referred to as neuroplasticity, like the neuroadaptations stimulated by other drugs of addiction, may stem from a cascade of neurobiological events governed by dopaminergic activity in corticolimbic-striatal circuits (Kalivas \& O'Brien, 2008). Acute administration of opioids results in dopamine release from the ventral tegmental area to the prefrontal cortex and nucleus accumbens (Center, 2011; Shippenberg, Bals-Kubik, \& Herz, 1993). This dopamingericallymediated process facilitates the learning of drug reward; when opioids result in pain relief, this signals the reward value of opioid-related stimuli (Becker et al., 2012), increasing their incentive salience (Robinson \& Berridge, 2008). In other words, the individual learns that opioids and opioid-related cues (e.g., the sight of a pill bottle, a prescription slip, or even the pharmacy where the opioids are dispensed) are motivationally salient, and should be sought after as a means of maintaining a positive hedonic tone. As chronic pain patients engage in recurrent opioid use or misuse, opioid cues may become salient through the pharmacologic reward induced by opioid consumption (positive reinforcement), as well as through the analgesic effects of the drug that remove or allay the aversive experience of pain (negative 
reinforcement) (Fields, 2004). The incentive salience of opioid cues may increase over time as opioid dependence is established via the process of sensitization of the mesolimbic dopamine system (Robinson \& Berridge, 2008). Such reward learning may be coupled with a strong drive towards opioids or a "wanting" that is independent of any "liking" or conscious preference for the drug (Berridge et al., 2009). In fact, many chronic pain patients express a strong dislike of opioids due to their side effects or the stigma associated with opioid use, yet the compulsion to take opioids increases despite this sentiment of disdain.

\subsection{Establishment of opioid misuse habits}

Over time, this transient neuroplasticity becomes more stable as individuals begin to form unconscious appetitive habits, mediated by structural and functional changes in corticolimbic-striatal circuits (Yin \& Knowlton, 2006). Modified striatal circuitry may govern the implicit neurocognitive operations that direct and impel addictive behaviors and craving states characteristic of disordered forms of substance use, including prescription opioid use disorders, (Stacy \& Wiers, 2010). Repeated substance use is thought to establish automatic drug-use action schemas (i.e., memory systems that compel and coordinate consumption of the substance through automatized sequences of stimulus-bound, context-dependent behavior, including the biasing of attention towards substance-relevant stimuli) (Garland, Boettiger, \& Howard, 2011; Pierce \& Vanderschuren, 2010; Tiffany, 1990). Insofar as cues associated with past drug use are motivationally salient for habitual drug users, they are able to consequently capture attention, which in turn amplifies their motivational salience (Franken, 2003). This phenomenon, known as addiction attentional bias, is associated with craving (Field, Munafo, \& Franken, 2009), increases drug use (Field \& Eastwood, 2005), and predicts relapse (Garland, Franken, \& Howard, 2011) among persons with alcohol and illicit drug dependence. A recent study from our laboratory demonstrated that chronic pain patients who met diagnostic criteria for opioid dependence exhibited a significant attentional bias towards prescription opioid cues (e.g., photographs of a pills or pill bottles) (Garland, Froeliger, Passik, \& Howard, 2012). Moreover, opioid attentional bias was positively correlated with opioid craving. When external (e.g., the sight of a pill bottle) or internal (e.g., pain, stress) cues associated with past opioid use capture attention, they may trigger dopamine release and activate habitual drug use routines subserved by neuroplastic alterations to cortico-limbic-striatal circuits (Everitt \& Robbins, 2005; Kalivas \& Volkow, 2005).

\subsection{Dysregulation of reward processing and default mode activity in opioid addiction}

As addictive automaticity is entrenched, neural circuits mediating associations between drug cues and learned appetitive responses become strengthened, while non-drug-related learning is diminished (Hyman, 2005; Kalivas \& O’Brien, 2008; Kalivas \& Volkow, 2005). Thus, recurrent opioid use may lead to insensitivity in the dopamine system toward natural rewards, like food, sex, or social affiliation (Volkow et al., 2011). Indeed, decreased responsiveness to natural reinforcers has been observed among opiate dependent individuals (Lubman, Allen, Peters, \& Deakin, 2008) and is robustly predictive of future opiate consumption (Lubman et al., 2009). Thus, the addictive cycle becomes more and more insidious as both the pain threshold and the ability to experience natural pleasure decreases. Indeed, increased sensitization to pain, when coupled with tolerance to the analgesic effects of opioids, can result in increased opioid craving (Ren, Shi, Epstein, Wang, \& Lu, 2009) and consumption (Martell et al., 2007). Furthermore, pain itself may decrease responsiveness to natural rewards, resulting in blunted dopaminergic responses to naturally-rewarding stimuli and anhedonia (Becker et al., 2012; Leknes \& Tracey, 2008). As a result of increasing hyperalgesia and anhedonia, the normative affective balance is tipped towards negativity, further propelling the downward spiral of pain and opioid addiction. 
This downward spiral may also crucially involve maladaptive patterns of self-referential thought and aberrant default mode processes as the healthy sense of identity transmogrifies into a self-concept entrapped by pain and entangled with dependence on opioid analgesia. Recent findings provide evidence for dysfunctional default mode-related neural function in opiate addicts, characterized by strong functional connectivity between the nucleus accumbens and prefrontal cortex coupled with attenuated functional connectivity between the prefrontal cortex and anterior cingulate cortex (Ma et al., 2010), a brain structure whose cognitive control functions are significantly impaired in opiate addicts (Yücel et al., 2007). Similarly, chronic pain patients reporting greater pain exhibit decreased connectivity between the default mode network and the anterior cingulate cortex (Loggia et al., in press). Speculatively, similar changes in self-referential, executive, and reward circuitry might underlie the transition from opioid use to misuse and addiction, as the patient's sense of self and autobiographical narrative becomes more entrenched in the downward spiral of seeking relief from pain through opioids. It is likely that interactions between sensory, cognitive, and self-referential processes fuel the progression toward addictive use of opioids among chronic pain patients.

\section{Pain, Negative Emotion, and Opioid Addiction}

\subsection{Emotional modulation of pain}

The aversive nature of pain elicits a powerful emotional reaction that feeds back to modulate pain perception. Pain is often accompanied by feelings of anger, sadness and fear depending on how the pain is cognitively appraised. Persistent negative evaluations of noxious sensory events can lead to pain catastrophizing, where the individual interprets uncomfortable or even innocuous somatic sensations as indicating the presence of a serious or mortal threat and consequently underestimate their ability to cope with those respective sensations. These experiences illustrate the importance of cognitive appraisal processes in the construction of the subjective experience of pain. Catastrophic appraisals are largely mediated by fear and produce an intensified pain or allodynia which can result in greater functional disability and reduced quality of life (Crombez et al., 1999; Turner, Jensen, Warms, \& Cardenas, 2002).

Brain regions involved in the processing negative affect are also associated with processing the subjective experience of pain. These areas include executive-level brain regions such as the anterior cingulate and prefrontal cortex and sensory and self-evaluatory regions such as the anterior insula (Craig, 2003; Wiech \& Tracey, 2009). Thus, when individuals experience pain-related negative emotions, the heightened neural processing of threat produces a precognitive mental set that primes the individual for an exacerbated subjective experience of pain (De Wied \& Verbaten, 2001; Kirwilliam \& Derbyshire, 2008; Ploner, Lee, Wiech, Bingel, \& Tracey, 2010) and subsequently increases the likelihood that innocuous somatic sensations will be interpreted as painful (Bogaerts, Janssens, De Peuter, Van Diest, \& Van den Bergh, 2009; Panerai, 2011; Strigo, Simmons, Matthews, Craig, \& Paulus, 2008).

The fear of pain, a clinical feature of chronic pain patients, is associated with hypervigilance for and sustained attention to pain-related stimuli (Haggman, Sharpe, Nicholas, \& Refshauge, 2010; Keogh, Ellery, Hunt, \& Hannent, 2001). Thus, negative affect biases attention toward pain, which then increases its aversive quality. Activation of the neural circuitry subserving negative affect, stress and pain disrupts the function of brain circuits that govern cognitive control (i.e., circuits governed by regions of prefrontal cortex), which may reduce the ability to regulate pain using higher-order cognitive coping strategies like reappraisal or viewing the pain as controllable (Arnsten, 2009; Lawrence, Hoeft, Sheau, \& Mackey, 2011). Furthermore, stress and negative affect intensify sympathetic nervous system activity associated with pain, manifested in increased anxiety, heart rate, skin conductance responses, and muscle tension that is perceived as painful muscle spasms (Flor, 
Turk, \& Birbaumer, 1985; Lundberg et al., 1999; Tousignant-Laflamme \& Marchand, 2006). Thus, negative affective states may result from chronic pain and feed back into biobehavioral processes that amplify pain perception (Loggia et al., 2012; Ploner et al., 2010) and exacerbate suffering. Concomitantly, negative affect predicts increased opioid craving among long-term opioid users (Wasan et al., 2012) and is associated with initiation and continued misuse of prescribed opioids (Sullivan, Edlund, Zhang, Unutzer, \& Wells, 2006). Opioid misusers may use opioids to self-medicate (Khantzian, 1997) the negative affective states and autonomic arousal that cause, co-occur with, or result from pain (Jänig $\&$ Habler, 2000; Martenson, Cetas, \& Heinricher, 2009). In turn, self-medication of negative emotions with opioids may promote the development of opioid addiction.

\subsection{Allostasis and the downward spiral of chronic pain and opioid addiction}

Negative emotions may contribute to the development of addiction through the progressive dysregulation of stress and reward circuitry in the extended amygdala and altered neurotransmitter function characterized by increased recruitment of other brain arousalstress systems (Koob \& Le Moal, 2008; Koob, 2009; R. J. Smith \& Aston-Jones, 2008). These systems are thought to mediate not only stress but also antireward - that is, a homeostatic process whereby brain systems maintain reward within a given limit or set point (Koob \& Le Moal, 1997, 2001, 2008). According to Koob and LeMoal's allostatic model of addiction $(1997,2001)$, use of substances to compensate for dysphoria results in an opponent process that leads to neurobiological sensitization in the extended amygdala and the brain arousal-stress systems to threat and harm, while sensitivity to reward is decreased. Thus, in addiction, homeostasis is broken, leading to a chronic deviation of brain systems from their normal operating level, termed allostasis. This shift in reward threshold, induced by activation of brain antireward systems may then elicit increased consumption of psychoactive substances as a means of achieving a hedonic equilibrium. Ironically, this attempt to reach a hedonic state comes with a cost: the continued use of substances further increases the reward set point in the brain, making the individual increasingly insensitive to naturally-rewarding experiences while becoming increasingly sensitive to punishment, pain, and other aversive states (Koob \& Le Moal, 2008). Thus, load incurred from prior injury and enhanced by the pharmacological effects of psychoactive substances promotes neuroadaptation to drug effects, modulates sensitization to rewards and punishment, and intensifies negative mood states and pain. Thus, in addition to hyperalgesia, prolonged misuse of opioids to medicate negative affective states and induce euphoria may result in hyperkatifeia, an increased sensitivity to emotional distress (Shurman et al., 2010). This cyclic process then elicits further substance use as a means of countering dysphoric mood (see Figure 1). Recurrent use of opioids to maintain positive emotional functioning in the face of stress and pain may result in a shift in the hedonic set point of the brain such that the individual becomes increasingly dependent on opioids to maintain a sense of psychological well-being. In turn, the sense of self may become more entangled with narratives of pain and opioid use.

As the cycle spirals further downward, the experience of pain may cue habitual drug use routines, even when they have been rendered ineffectual due to increased tolerance to opioid analgesia. Although chronic use of opioids may produce limited analgesic effects, once the habit of opioid misuse has been established, it may continue despite countervailing health, social, and legal reasons to adhere to the prescribed medication regimen. Thus, pain comes to trigger the automatic reaction (i.e. taking medication at higher than prescribed doses), and the conscious decision to take the medication is no longer the dominant factor in opioid use. Unconscious habits replace conscious consideration and deliberate evaluation of the level of pain as the primary determinate of opioid dosing. Addictive opioid use may capitalize on non-drug striatal habit mechanisms, which, once established, operate in the absence of 
pharmacologic reward or drug-induced disruption of normal control (Graybiel, 2008). In other words, whether or not opioid use works to relieve pain (or even produces hyperalgesia), it may persist as an ingrained habit triggered by sensations of pain and external drug-related cues which were originally imbued with motivational salience during the acquisition of the habit of opioid use (Wood \& Neal, 2007). This rigid, scripted response to contextual conditions, known as mindlessness (Langer, 1992), may fuel the downward spiral of chronic pain, suffering, and opioid addiction.

When access to opioids is restricted despite the presence of pain and addictive cues, opioid dependent individuals may experience an intensely aversive craving state, characterized by dysphoria, anxiety, and craving coupled with somatic symptoms of withdrawal that drives an obsessive or intrusive preoccupation with obtaining opioids (Shurman et al., 2010). These experiences promote addictive use of opioids as dependent individuals may feel impelled to avoid the discomfort, dysphoria and psychic distress that accompany withdrawal.

Compulsive consumption of opioids to satisfy craving and allay withdrawal irrespective of the presence of actual injury or tissue damage may be seen as a hallmark of addiction among pain patients.

\section{Clinical Implications}

In light of the complex, insidious processes outlined in this paper, multimodal interventions are needed to target the manifold links in the risk chain between chronic pain and prescription opioid addiction. Novel therapies that can facilitate attentional regulation of opioid cue-reactivity and enhance positive emotion while ameliorating pain may be efficacious means of addressing this pernicious and prevalent social problem. In that regard, mindfulness-based therapies, which are held to strengthen attentional control and temper emotional reactivity (Hölzel et al., 2011; Vago \& Silbersweig, 2013), may be especially promising.

We hypothesize that mindfulness training may interrupt the downward spiral linking pain to addictive use of opioids in the following ways. Moving down the spiral (see Figure 1) from top to bottom, mindfulness training may first reduce the severity and unpleasantness of chronic pain (Chiesa \& Serretti, 2011; Gaylord et al., 2011; Rosenzweig et al., 2010; Zeidan et al., 2011) by attenuating emotionally-aversive appraisals of pain sensations and decreasing pain sensitivity (Garland, Gaylord, et al., 2011; Zeidan, Grant, Brown, McHaffie, $\&$ Coghill, 2012). Second, due to its facilitative effects on attentional re-orienting capacity (Jha, Krompinger, \& Baime, 2007) mindfulness may reduce attentional fixation on and hypervigilance for pain (Vago \& Nakamura, 2012; Garland \& Howard, in press). Third, because mindfulness involves adopting a nonjudgmental stance towards emotional experience (Hölzel et al., 2011), mindfulness may decrease negative emotional reactivity (Froeliger, Garland, Modlin, \& McClernon, 2012), thereby reducing pain catastrophizing (Garland, Gaylord, et al., 2011) and preventing the need to self-medicate stress and negative emotions with opioids. Fourth, mindfulness may lessen addiction attentional bias (Garland, Boettiger, Gaylord, Chanon, \& Howard, 2012; Garland, Gaylord, Boettiger, \& Howard, 2010), and, as such, reduce biased processing of prescription opioid-related cues. Fifth, mindfulness may decrease craving (Bowen et al., 2009) by attenuating bottom-up reactivity to drug-related stimuli (Westbrook et al., 2011) and decoupling negative affect from the urge to use substances (Witkiewitz \& Bowen, 2011). Sixth, mindfulness may enhance positive affect and hedonic processing (Geschwind, Peeters, Drukker, Van Os, \& Wichers, 2011), undoing the insensitivity to natural reward that fuels increasing dependence on opioids. Seventh, mindfulness may decrease habit behavior (Wenk-Sormaz, 2005) and reduce rigid adherence to scripted cognitive responses (Greenberg et al., 2012), resulting in enhanced cognitive control of compulsive and habitual opioid use. Lastly, mindfulness may aid in 
regulating pain-primed mental states and self-referential processes that have been found to exacerbate and prolong the subjective experience of chronic pain (Loggia et al., 2012). In that regard, studies suggest that mindfulness practice is associated with decreased selfreferential activations in cortical midline brain structures (Farb, Segal, Mayberg, Bean, McKeon, Fatima, \& Anderson, 2007), reduced default mode processing (Brewer et al., 2011) and increased functional connectivity between default mode networks and attentional networks (Froeliger et al., 2012). Through these therapeutic pathways, mindfulness-based interventions might help to disrupt and reverse the cycle of maladaptive pain coping habits and aberrant drug-seeking behaviors that comprise the downward spiral of pain and opioid addiction.

Though mindfulness-based approaches are relatively novel means of addressing cooccurring pain and opioid misuse, cognitive-behavioral therapy (CBT) has been used for more than three decades to treat chronic pain syndromes. As early as 1976 Fordyce advanced a behavioral model of pain management focused on operant conditioning, reinforcement of functional behaviors, and progressive relaxation (Fordyce, 1976). Modern CBT, which combines behavioral techniques with challenging of maladaptive thoughts contributing to pain catastrophizing and addictive behavior, have been shown to enhance coping with pain (Morley, Williams, \& Hussain, 2008) and reduce substance misuse (Magill \& Ray, 2009). A systematic review and meta-analysis conducted by Williams, Eccleston, \& Morley (2012) indicated that CBT produced small to medium effect size improvements in pain, disability, and mood .

In addition, research on positive psychology suggests that savoring pleasant experiences can induce motivation and increase positive emotions (Quoidback, Berry, Hansenne, \& Mikolajczak, 2010), which in turn are associated with decreased pain hypervigilance and fear of pain (Crombez, Viane, Eccleston, Devulder, \& Goubert, 2012). A host of basic biobehavioral research studies support the presence of positive affect analgesia. In healthy subjects, presentation of positive affective photographs produced greater pain tolerance on a cold pressor task than neutral and negative affective photos (de Wied \& Verbaten, 2001). Positive affect analgesia has also been observed following induction of positive affect through other means including: humorous (Weisenberg, Raz, \& Hener, 1998) and romantic films (Zillman, de Wid, King-Jablonski, Jenzowsky, 1996), laughter (Cogan et al., 1987), and pleasant music (Silvestrini et al., 2011). Moreover, induction of positive affect through therapeutic suggestion (Zelman et al., 1991) and guided imagery (Bruehl, Carlson, McCubbin, 1993) has also been shown to reduce pain. It is unknown to what extent positive affect analgesia may influence chronic pain.

Multimodal interventions that capitalize on these combined therapeutic approaches might be especially efficacious. In one of the first, well-controlled studies of a psychological treatment for chronic pain patients at high risk for misusing opioids, Jamison and colleagues (2010) conducted a randomized controlled trial of a multimodal intervention that combined cognitive-behavioral (e.g., coping with urges, problem solving) and motivational elements (e.g., maintaining abstinence motivations, balancing fleeting versus durable satisfactions) to decrease prescription opioid misuse and increase medication compliance. Significantly fewer high-risk individuals randomly assigned to this experimental intervention misused opioids at a six-month follow-up than those assigned to a standard medical care condition. Though most were satisfied with the study treatment, less than one-third of participants felt that it improved their pain.

To address this unmet need, Mindfulness-Oriented Recovery Enhancement (MORE; Garland, 2013), unites complementary aspects of mindfulness training, CBT, and principles from positive psychology into an integrative approach to treating co-occurring chronic pain 
and prescription opioid misuse. Recent findings from a randomized controlled trial demonstrate that MORE led to significant reductions in pain attentional bias coupled with decreased emotional reactivity and increased perceived control over pain in a sample of chronic pain patients receiving long-term opioid therapy, many of whom were opioid misusers (Garland \& Howard, in press). New clinical outcome data from this trial suggest that MORE may significantly reduce pain severity and functional interference while decreasing opioid misuse and craving (Garland, Manusov, Froeliger, Williams, Kelly, Mann, \& Howard, 2013). Whether mindfulness training or other forms of behavioral intervention can disrupt the downward spiral of chronic pain and opioid addiction is an open question to be explored in future clinical research.

\section{Conclusion}

In summary, we theorize that the problem of co-occurring chronic pain and opioid addiction involves a cycle of behavioral escalation where nociception and stress trigger hypervigilance and catastrophizing, amplifying pain and provoking recurrent self-medication with opioids, which in turn biases attention towards opioid-related cues that come to elicit the habit of drug use despite ever diminishing analgesia. Uncontrolled use of opioids coupled with chronic pain dysregulates reward processing in the brain, depriving the individual from experiencing pleasure from objects and events in the natural environment. As the sense of self becomes ensnared in pain-laden narratives and entrapped by a compulsive drive for relief, this downward spiral may result in a loss of control over opioid use and increasing reliance on opioids to maintain an ever-diminishing sense of well-being.

\section{Acknowledgments}

This work was supported by grant DA032517 awarded to E.L.G. The authors wish to acknowledge Dr. Norman Farb for providing the unlabeled shape used to generate the downward spiral model in Figure 1.

\section{REFERENCES}

Amari E, Rehm J, Goldner E, Fischer B. Nonmedical prescription opioid use and mental health and pain comorbidities: A narrative review. Can. J. Psychiatry. 2011; 56:495-502. [PubMed: 21878161]

Apkarian AV, Bushnell MC, Treede RD, Zubieta JK. Human brain mechanisms of pain perception and regulation in health and disease. Eur. J. Pain. 2005; 9:463-463. [PubMed: 15979027]

Arnsten AF. Stress signaling pathways that impair prefrontal cortex structure and function. Nat. Rev. Neurosci. 2009; 10:410-422. [PubMed: 19455173]

Arvidsson U, Dado RJ, Riedl M, Lee JH, Law PY, Loh HH, Elde R, Wessendorf MW. Delta-opioid receptor immunoreactivity: distribution in brainstem and spinal cord, and relationship to biogenic amines and enkephalin. J. Neurosci. 1995; 15:1215-1235. [PubMed: 7532700]

Baldacchino A, Balfour DJK, Passetti F, Humphris G, Matthews K. Neuropsychological consequences of chronic opioid use: A quantitative review and meta-analysis. Neurosci. Biobehav. Rev. 2012; 36:2056-2068. [PubMed: 22771335]

Baliki MN, Chialvo DR, Geha PY, Levy RM, Harden RN, Parrish TB, Apkarian AV. Chronic pain and the emotional brain: specific brain activity associated with spontaneous fluctuations of intensity of chronic back pain. J. Neurosci. 2006; 26:12165-12173. [PubMed: 17122041]

Becerra L, Harter K, Gonzalez RG, Borsook D. Functional magnetic resonance imaging measures of the effects of morphine on central nervous system circuitry in opioid-naive healthy volunteers. Anesthes.Analges. 2006; 103:208-216.

Becker S, Gandhi W, Schweinhardt P. Cerebral interactions of pain and reward and their relevance for chronic pain. Neurosci. Lett. 2012; 520:182-187. [PubMed: 22440855]

Berridge KC, Robinson TE, Aldridge JW. Dissecting components of reward: "liking”, "wanting”, and learning. Curr. Opin. Pharmacology. 2009; 9:65-73.

Besson JM. The neurobiology of pain. Lancet. 1999; 353:1610-1615. [PubMed: 10334274] 
Bogaerts K, Janssens T, De Peuter S, Van Diest I, Van den Bergh O. Negative affective pictures can elicit physical symptoms in high habitual symptom reporters. Psychol. Health. 2009; 25:685-698. [PubMed: 20204961]

Bowen S, Chawla N, Collins SE, Witkiewitz K, Hsu S, Grow J, Marlatt A. Mindfulness-based relapse prevention for substance use disorders: A pilot efficacy trial. Subst. Abuse. 2009; 30:295-305.

Breiter HC, Gollub RL, Weisskoff RM, Kennedy DN, Makris N, Berke JD, Goodman JM, Kantor HL, Gastfriend DR, Riorden JP, Mathew RT, Rosen BR, Hyman SE. Acute effects of cocaine on human brain activity and emotion. Neuron. 1997; 19:591-611. [PubMed: 9331351]

Brewer JA, Worhunsky PD, Gray JR, Tang Y-Y, Weber J, Kober H. Meditation experience is associated with differences in default mode network activity and connectivity. PNAS. 2011; 108:20254-20259. [PubMed: 22114193]

Bruehl S, Carlson CR, McCubbin JA. Two brief interventions for acute pain. Pain. 1993; 54:29-36. [PubMed: 8378100]

Butler SF, Budman SH, Fernandez KC, Houle B, Benoit C, Katz N, Jamison RN. Development and validation of the Current Opioid Misuse Measure. Pain. 2007; 130:144-156. [PubMed: 17493754]

Center MP. Pharmacology of opioids in the treatment of chronic pain syndromes. Pain Physician. 2011; 14:E343-E360. [PubMed: 21785485]

Cherrier MM, Amory JK, Ersek M, Risler L, Shen DD. Comparative cognitive and subjective side effects of immediate-release oxycodone in healthy middle-aged and older adults. J. Pain. 2009; 10:1038-1050. [PubMed: 19729346]

Chiara GD, North RA. Neurobiology of opiate abuse. Trends Pharm. Sci. 1992; 13:185-193. [PubMed: 1604711]

Chiesa A, Serretti A. Mindfulness-based interventions for chronic pain: A systematic review of the evidence. J. Alt. Complem. Med. 2011; 17:83-93.

Chu LF, Angst MS, Clark D. Opioid-induced hyperalgesia in humans: molecular mechanisms and clinical considerations. Clin. J. Pain. 2008; 24:479-496. [PubMed: 18574358]

Cogan R, Cogan D, Waltz W, McCue M. Effects of laughter and relaxation on discomfort thresholds. J. Beh. Med. 1987; 10:139-144.

Coghill RC, McHaffie JG, Yen YF. Neural correlates of interindividual differences in the subjective experience of pain. PNAS. 2003; 100:8538-8542. [PubMed: 12824463]

Craig AD. Interoception: the sense of the physiological condition of the body. Curr. Opin. Neurobiol. 2003; 13:500-505. [PubMed: 12965300]

Crombez G, Viane I, Eccleston C, Devulder J, Goubert L. Attention to pain and fear of pain in patients with chronic pain. J. Behav. Med. 2012

Crombez G, Vlaeyen JWS, Heuts PHTG, Lysens R. Pain-related fear is more disabling than pain itself: evidence on the role of pain-related fear in chronic back pain disability. Pain. 1999; 80:329-339. [PubMed: 10204746]

De Wied M, Verbaten MN. Affective pictures processing, attention, and pain tolerance. Pain. 2001; 90:163-172. [PubMed: 11166983]

Dellemijn PL, Vanneste JA. Randomised double-blind active-placebo-controlled crossover trial of intravenous fentanyl in neuropathic pain. Lancet. 1997; 349:753-758. [PubMed: 9074573]

Denisco RA, Chandler RK, Compton WM. Addressing the intersecting problems of opioid misuse and chronic pain treatment. Exp. Clin. Psychopharm. 2008; 16:417-428.

Edwards RR, Wasan AD, Michna E, Greenbaum S, Ross E, Jamison RN. Elevated pain sensitivity in chronic pain patients at risk for opioid misuse. J. Pain. 2011; 12:953-963. [PubMed: 21680252]

Everitt BJ, Robbins TW. Neural systems of reinforcement for drug addiction: from actions to habits to compulsion. Nat. Neurosci. 2005; 8:1481-1489. [PubMed: 16251991]

Farb NA, Segal ZV, Mayberg H, Bean J, McKeon D, Fatima Z, et al. Attending to the present: Mindfulness meditation reveals distinct neural modes of self-reference. Soc. Cog. Affect. Neurosci. 2007; 2:313-322.

Field M, Eastwood B. Experimental manipulation of attentional bias increases the motivation to drink alcohol. Psychopharm. 2005; 183:350-357. 
Field M, Munafo MR, Franken IH. A meta-analytic investigation of the relationship between attentional bias and subjective craving in substance abuse. Psychol. Bull. 2009; 135:589-607. [PubMed: 19586163]

Fields HL. Mu opioid receptor mediated analgesia and reward. The Opiate Receptors. 2011:239-264.

Fiset P, Plourde G, Backman SB. Brain imaging in research on anesthetic mechanisms: Studies with propofol. Prog. Brain Res. 2005; 150:245-250. [PubMed: 16186028]

Fishbain DA, Cole B, Lewis J, Rosomoff HL, Rosomoff RS. What percentage of chronic nonmalignant pain patients exposed to chronic opioid analgesic therapy develop abuse/addiction and/or aberrant drug-related behaviors? A structured evidence-based review. Pain Med. 2007; 9:444-459. [PubMed: 18489635]

Flor H, Turk DC, Birbaumer N. Assessment of stress-related psychophysiological reactions in chronic back pain patients. J. Consult. Clin. Psychol. 1985; 53(3):354-364. [PubMed: 3159767]

Fordyce, WE. Behavioral methods for chronic pain and illness. Mosby; St. Louis, MO: 1976.

Franken IH. Drug craving and addiction: integrating psychological and neuropsychopharmacological approaches. Prog. Neuropsychopharm. Biol. Psychiatry. 2003; 27:563-579.

Froeliger B, Garland EL, Kozink RV, Modlin LA, Chen NK, McClernon FJ, Greeson JM, Sobin P. Meditation-state functional connectivity $(\mathrm{msFC})$ : Strengthening of the dorsal attention network and beyond. Evidence-Based Complem. Alt. Med. 2012

Froeliger BE, Garland EL, Modlin LA, McClernon FJ. Neurocognitive correlates of the effects of yoga meditation practice on emotion and cognition: a pilot study. Front. Integ. Neurosci. 2012; 6:48.

Garland EL. Pain processing in the human nervous system: a selective review of nociceptive and biobehavioral pathways. Primary Care Clin. North Am. 2012; 39:561.

Garland, EL. Mindfulness-Oriented Recovery Enhancement for addiction, stress, and pain. NASW Press; Washington, DC: 2013.

Garland EL, Boettiger CA, Howard MO. Targeting cognitive-affective risk mechanisms in stressprecipitated alcohol dependence: An integrated, biopsychosocial model of allostasis, automaticity, and addiction. Med. Hypotheses. 2011; 76:745-754. [PubMed: 21354711]

Garland EL, Boettiger C, Gaylord S, Chanon V, Howard M. Mindfulness is inversely associated with alcohol attentional bias among recovering alcohol-dependent adults. Cog. Ther. Res. 2012; 36:441-450.

Garland EL, Franken IHA, Howard MO. Cue-elicited heart rate variability and attentional bias predict alcohol relapse following treatment. Psychopharm. 2012; 222:17-26.

Garland EL, Froeliger B, Passik S, Howard M. Attentional bias for prescription opioid cues among opioid dependent chronic pain patients. J. Behav. Med. 2012:1-10.

Garland EL, Gaylord SA, Boettiger CA, Howard MO. Mindfulness training modifies cognitive, affective, and physiological mechanisms implicated in alcohol dependence: Results from a randomized controlled pilot trial. J. Psychoact. Drugs. 2010; 42:177-192.

Garland EL, Gaylord SA, Palsson O, Faurot K, Douglas Mann J, Whitehead WE. Therapeutic mechanisms of a mindfulness-based treatment for IBS: effects on visceral sensitivity, catastrophizing, and affective processing of pain sensations. J. Behav. Med. 2011:1-12.

Garland, EL.; Howard, MO. Psychother. Psychosomatics. Mindfulness-Oriented Recovery Enhancement reduces pain attentional bias in chronic pain patients. in press

Garland EL, Manusov E, Froeliger BE, Williams J, Kelly A, Mann JD, Howard MO. MindfulnessOriented Recovery Enhancement for chronic pain and prescription opioid misuse: Results from a randomized controlled trial. Manuscript submitted for publication. 2013

Gaylord SA, Palsson OS, Garland EL, Faurot KR, Coble RS, Mann JD, Frey W, Whitehead WE. Mindfulness training reduces the severity of irritable bowel syndrome in women: Results of a randomized controlled trial. Amer. J. Gastroenterol. 2011; 106:1678-1688. [PubMed: 21691341]

Geschwind N, Peeters F, Drukker M, Van Os J, Wichers M. Mindfulness training increases momentary positive emotions and reward experience in adults vulnerable to depression: A randomized controlled trial. J. Consult. Clin. Psychol. 2011; 79:618-628. [PubMed: 21767001]

Graybiel AM. Habits, rituals, and the evaluative brain. Ann. Rev. Neurosci. 2008; 31:359-387. [PubMed: 18558860] 
Greenberg J, Reiner K, Meiran N. "Mind the Trap": Mindfulness practice reduces cognitive rigidity. PloS one. 2012; 7:e36206. [PubMed: 22615758]

Haggman SP, Sharpe LA, Nicholas MK, Refshauge KM. Attentional biases toward sensory pain words in acute and chronic pain patients. J. Pain. 2010; 11:1136-1145. [PubMed: 20797918]

Hall AJ, Logan JE, Toblin RL, Kaplan JA, Kraner JC, Bixler D, Paulozzi LJ. Patterns of abuse among unintentional pharmaceutical overdose fatalities. JAMA. 2008; 300:2613-2620. [PubMed: 19066381]

Heinricher M, Tavares I, Leith J, Lumb B. Descending control of nociception: Specificity, recruitment and plasticity. Brain Res. Rev. 2009; 60:214-225. [PubMed: 19146877]

Hellström C. Temporal dimensions of the self-concept: Entrapped and possible selves in chronic pain. Psychol. Health. 2001; 16:111-124.

Hölzel BK, Lazar SW, Gard T, Schuman-Olivier Z, Vago DR, Ott U. How does mindfulness meditation work? Proposing mechanisms of action from a conceptual and neural perspective. Persp. Psychol. Sci. 2011; 6:537-559.

Huang B, Dawson DA, Stinson FS, Hasin DS, Ruan W, Saha TD, Grant BF. Prevalence, correlates, and comorbidity of nonmedical prescription drug use and drug use disorders in the United States: Results of the National Epidemiologic Survey on Alcohol and Related Conditions. J. Clin. Psychiatry. 2006; 67:1062-1073. [PubMed: 16889449]

Hyman SE. Addiction: a disease of learning and memory. Amer. J. Psychiatry. 2005; 162:1414-1422. [PubMed: 16055762]

Ives TJ, Chelminski PR, Hammett-Stabler CA, Malone RM, Perhac JS, Potisek NM, Pignone MP. Predictors of opioid misuse in patients with chronic pain: a prospective cohort study. BMC Health Serv. Res. 2006; 6:46. [PubMed: 16595013]

Jamison RN, Butler SF, Budman SH, Edwards RR, Wasan AD. Gender differences in risk factors for aberrant prescription opioid use. J. Pain. 2010; 11:312. [PubMed: 19944648]

Jamison RN, Link CL, Marceau LD. Do pain patients at high risk for substance misuse experience more pain? A longitudinal outcomes study. Pain Med. 2009; 10:1084-94. [PubMed: 19671087]

Jänig W, Habler HJ. Sympathetic nervous system: Contribution to chronic pain. Prog. Brain Res. 2000; 129:451-468. [PubMed: 11098710]

Jastrzab L, Mackey S, Chu L, Stringer E, Younger J. Neural correlates of opioid induced hyperalgesia. J. Pain. 2012; 13:S51.

Jha AP, Krompinger J, Baime MJ. Mindfulness training modifies subsystems of attention. Cog. Affect. Behav. Neurosci. 2007; 7:109-119.

Johnson SW, North RA. Opioids excite dopamine neurons by hyperpolarization of local interneurons. J. Neurosci. 1992; 12:483-488. [PubMed: 1346804]

Julien, RM. A primer of drug action: a comprehensive guide to the actions, uses, and side effects of psychoactive drugs. 11th. Worth Publishers; New York, NY: 2007.

Kalivas PW, O’Brien. Drug addiction as a pathology of staged neuroplasticity. C. Neuropsychopharm. 2008; 33:166-180.

Kalivas PW, Volkow ND. The neural basis of addiction: A pathology of motivation and choice. Amer. J. Psychiatry. 2005; 162:1403-1413. [PubMed: 16055761]

Kendall SE, Sjøgren P, Pimenta CA, Højsted J, Kurita GP. The cognitive effects of opioids in chronic non-cancer pain. Pain. 2010; 150:225. [PubMed: 20554115]

Keogh E, Ellery D, Hunt C, Hannent I. Selective attentional bias for pain-related stimuli amongst pain fearful individuals. Pain. 2001; 91:91-100. [PubMed: 11240081]

Khantzian EJ. The self-medication hypothesis of substance use disorders: A reconsideration and recent applications. Harvard Rev. Psychiatry. 1997; 4:231-44.

Kirwilliam SS, Derbyshire SWG. Increased bias to report heat or pain following emotional priming of pain-related fear. Pain. 2008; 137:60-65. [PubMed: 17881129]

Koob GF. Neurobiological substrates for the dark side of compulsivity in addiction. Neuropharm. 2009; 56:18-31.

Koob GF, Le Moal M. Drug abuse: hedonic homeostatic dysregulation. Science. 1997; 278:52-58. [PubMed: 9311926] 
Koob GF, Le Moal M. Drug addiction, dysregulation of reward, and allostasis. Neuropsychopharm. 2001; 24:97-129.

Koob GF, Le Moal M. Addiction and the brain antireward system. Ann. Rev. Psychol. 2008; 59:29_ 53. [PubMed: 18154498]

Langer EJ. Matters of mind: Mindfulness/mindlessness in perspective. Conscious. Cog. 1992; 1:289_ 305.

Larance B, Degenhardt L, Lintzeris N, Winstock A, Mattick R. Definitions related to the use of pharmaceutical opioids: Extramedical use, diversion, non-adherence and aberrant medicationrelated behaviours. Drug Alcohol Rev. 2011; 30:236-245. [PubMed: 21545553]

Lawrence JM, Hoeft F, Sheau KE, Mackey SC. Strategy-dependent dissociation of the neural correlates involved in pain modulation. Anesthesiol. 2011; 115:844-851.

Le Bars D, Guilbaud G, Chitour D, Besson JM. Does systemic morphine increase descending inhibitory controls of dorsal horn neurones involved in nociception? Brain Res. 1980; 202:223228. [PubMed: 6253026]

Le Merrer J, Becker JAJ, Befort K, Kieffer BL. Reward processing by the opioid system in the brain. Physiol. Rev. 2009; 89:1379-1412. [PubMed: 19789384]

Lee MC, Wanigasekera V, Tracey I. Imaging opioid analgesia in the human brain. Trends Anaesthesia Crit. Care. 2012; 2:244-248.

Leknes S, Tracey I. A common neurobiology for pain and pleasure. Nat. Rev. Neurosci. 2008; 9:314320. [PubMed: 18354400]

Leppä M, Korvenoja A, Carlson S, Timonen P, Martinkauppi S, Ahonen J, Rosenberg PH, Aronen HJ, Kalso E. Acute opioid effects on human brain as revealed by functional magnetic resonance imaging. NeuroImage. 2006; 31:661-669. [PubMed: 16459107]

Lewis ME, Pert A, Pert CB, Herkenham M. Opiate receptor localization in rat cerebral cortex. J. Comparative Neurol. 1983; 216:339-358.

Loeser JD, Melzack R. Pain: an overview. Lancet. 1999; 353:1607-1609. [PubMed: 10334273]

Loggia ML, Kim J, Gollub RL, Vangel MG, Kirsch I, Kong J, Napadow V. Default mode network connectivity encodes clinical pain: An arterial spin labeling study. Pain. 2012 Advance online publication. doi: 10.1016/j.pain.2012.07.029.

Lubman DI, Allen NB, Peters LA, Deakin JF. Electrophysiological evidence that drug cues have greater salience than other affective stimuli in opiate addiction. J. Psychopharmcol. 2008; 22:83642.

Lubman DI, Yucel M, Kettle JW, Scaffidi A, Mackenzie T, Simmons JG, Allen NB. Responsiveness to drug cues and natural rewards in opiate addiction: associations with later heroin use. Arch. Gen. Psychiatry. 2009; 66:205-12. [PubMed: 19188543]

Lundberg U, Dohns IE, Melin B, Sandsjö L, Palmerud G, Kadefors R, Ekstrom M, Parr D. Psychophysiological stress responses, muscle tension, and neck and shoulder pain among supermarket cashiers. J. Occ. Health Psychol. 1999; 4:245-255.

Ma N, Liu Y, Li N, Wang CX, Zhang H, Jiang XF, Xu HS, Fu XM, Hu X, Zhang DR. Addiction related alteration in resting-state brain connectivity. Neuroimage. 2010; 49:738-744. [PubMed: 19703568]

Magill M, Ray LA. Cognitive-behavioral treatment with adult alcohol and illicit drug users: A metaanalysis of randomized controlled trials. J. Stud. Alcohol Drugs. 2009; 70:516-527. [PubMed: 19515291]

Manubay JM, Muchow C, Sullivan MA. Prescription drug abuse: epidemiology, regulatory issues, chronic pain management with narcotic analgesics. Primary Care Clin. 2011; 38:71-76.

Martell BA, O’Connor PG, Kerns RD, Becker WC, Morales KH, Kosten TR, Fiellin DA. Systematic review: opioid treatment for chronic back pain: prevalence, efficacy, and association with addiction. Ann. Intern. Med. 2007; 146:116-127. [PubMed: 17227935]

Martenson ME, Cetas JS, Heinricher MM. A possible neural basis for stress-induced hyperalgesia. Pain. 2009; 142:236-244. [PubMed: 19232470]

Mathieu-Kia AM, Fan LQ, Kreek MJ, Simon EJ, Hiller JM. mu-, delta-and kappa-opioid receptor populations are differentially altered in distinct areas of postmortem brains of Alzheimer's disease patients. Brain Res. 2001; 893:121-134. [PubMed: 11223000] 
Melzack R. From the gate to the neuromatrix. Pain. 1999; 82:S121-S126. [PubMed: 10491980]

Melzack R, Wall PD. Pain mechanisms: a new theory. Science. 1965; 150:971-979. [PubMed: 5320816]

Mendelson J, Flower K, Pletcher MJ, Galloway GP. Addiction to prescription opioids: characteristics of the emerging epidemic and treatment with buprenorphine. Exp. Clin. Psychopharm. 2008; 165:435-441.

Mintzer MZ, Copersino ML, Stitzer ML. Opioid abuse and cognitive performance. Drug Alcohol Depend. 2005; 78:225-230. [PubMed: 15845327]

Morley S, Davies C, Barton S. Possible selves in chronic pain: self-pain enmeshment, adjustment and acceptance. Pain. 2005; 115:84-94. [PubMed: 15836972]

Morley S, Williams A, Hussain S. Estimating the clinical effectiveness of cognitive behavioural therapy in the clinic: Evaluation of a CBT informed pain management programme. Pain. 2008; 137:670-680. [PubMed: 18394806]

Novy DM, Lam C, Gritz ER, Hernandez M, Driver LC, Koyyalagunta D. Distinguishing features of cancer patients who smoke: pain, symptom burden, and risk for opioid misuse. J. Pain. 2012; 13:1058-1067. [PubMed: 23010143]

Oertel BG, Preibisch C, Wallenhorst T, Hummel T, Geisslinger G, Lanfermann H, L'otsch J. Differential opioid action on sensory and affective cerebral pain processing. Clin. Pharm. Ther. 2007; 83:577-588.

Ospina, M.; Harstall, C. Prevalence of chronic pain: An overview. Alberta Heritage Foundation for Medical Research; Alberta, CA: 2002.

Pan YX, Pasternak GW. Molecular biology of mu opioid receptors. The Opiate Receptors. 2011:121160.

Panerai AE. Pain emotion and homeostasis. Neurol. Sci. 2011; 32:27-29.

Pappas SS, Kennedy T, Goudreau JL, Lookingland KJ. Opioid-mediated regulation of A11 diencephalospinal dopamine neurons: pharmacological evidence of activation by morphine. Neuropharm. 2011; 61:614-621.

Passik, SD. Issues in long-term opioid therapy: unmet needs, risks, and solutions. Mayo Clin. Proceedings; 2009. p. 593-601.

Pierce RC, Vanderschuren L. Kicking the habit: The neural basis of ingrained behaviors in cocaine addiction. Neurosci. Biobehav. Rev. 2010; 35:212-219. [PubMed: 20097224]

Pincus T, Morley S. Cognitive-processing bias in chronic pain: A review and integration. Psychol. Bull. 2001; 127:599-617. [PubMed: 11548969]

Ploner M, Lee MC, Wiech K, Bingel U, Tracey I. Prestimulus functional connectivity determines pain perception in humans. PNAS. 2010; 107:355-360. [PubMed: 19948949]

Pohl M, Smith L. Chronic pain and addiction: Challenging co-occurring disorders. J. Psychoactive Drugs. 2012; 44:119-124. [PubMed: 22880539]

Prosser J, London ED, Galynker II. Sustained attention in patients receiving and abstinent following methadone maintenance treatment for opiate dependence: Performance and neuroimaging results. Drug Alcohol Depend. 2009; 104:228-240. [PubMed: 19608356]

Quoidback J, Berry EV, Hansenne M, Mikolajczak M. Positive emotion regulation and wellbeing: Comparing the impact of eight savoring and dampening strategies. Pers. Ind. Differences. 2010; 49:368-373.

Raichle ME, MacLeod AM, Snyder AZ, Powers WJ, Gusnard DA, Shulman GL. A default mode of brain function. PNAS. 2001; 98:676-682. [PubMed: 11209064]

Rainville P. Brain mechanisms of pain affect and pain modulation. Curr. Opin. Neurobiology. 2002; 12:195-204.

Ren ZY, Shi J, Epstein DH, Wang J, Lu L. Abnormal pain response in pain-sensitive opiate addicts after prolonged abstinence predicts increased drug craving. Psychopharm. 2009; 204:423-9.

Robinson TE, Berridge KC. The incentive sensitization theory of addiction: some current issues. Phil. Trans. Royal Soc. Lon. B. Biol. Sci. 2008; 363:3137-3146.

Rosenblum A, Marsch LA, Joseph H, Portenoy RK. Opioids and the treatment of chronic pain: controversies, current status, and future directions. Exp. Clin. Psychopharm. 2008; 16:405-416. 
Rosenzweig S, Greeson JM, Reibel DK, Green JS, Jasser SA, Beasley D. Mindfulness-based stress reduction for chronic pain conditions: variation in treatment outcomes and role of home meditation practice. J. Psychosomatic Res. 2010; 68:29-36.

Schneider U, Bevilacqua C, Jacobs R, Karst M, Dietrich DE, Becker H, Muller-Vahl, Seeland I, Gielsdorf D, Schedlowski M, Emrich HM. Effects of fentanyl and low doses of alcohol on neuropsychological performance in healthy subjects. K.R. Neuropsychobiol. 1999; 39:38-43.

Shippenberg TS, Bals-Kubik, Herz A. Examination of the neurochemical substrates mediating the motivational effects of opioids: role of the mesolimbic dopamine system and D-1 vs. D-2 dopamine receptors. R. J. Pharm. Exp. Ther. 1993; 265:53-59.

Shurman J, Koob GF, Gutstein HB. Opioids, pain, the brain, and hyperkatifeia: a framework for the rational use of opioids for pain. Pain Med. 2010; 11:1092-1098. [PubMed: 20545871]

Silvestrini N, Piguet V, Cedraschi C, Zentner MR. Music and auditory distraction reduce pain: Emotional or attentional effects? Music Med. 2011; 3:264-170.

Smith RJ, Aston-Jones G. Noradrenergic transmission in the extended amygdala: role in increased drug-seeking and relapse during protracted drug abstinence. Brain Structure Function. 2008; 213:43-61. [PubMed: 18651175]

Spiller R, Aziz Q, Creed F, Emmanuel A, Houghton L, Hungin P, Jones R, Kumar D, Rubin G, Trudgill N, Whorwell P. Guidelines on the irritable bowel syndrome: mechanisms and practical management. Gut. 2007; 56:1770-98. [PubMed: 17488783]

Stacy AW, Wiers RW. Implicit cognition and addiction: A tool for explaining paradoxical behavior. Ann. Rev. Clin. Psychol. 2010; 6:551-575. [PubMed: 20192786]

Strigo IA, Simmons AN, Matthews SC, Craig AD, Paulus MP. Increased affective bias revealed using experimental graded heat stimuli in young depressed adults: Evidence of "emotional allodynia". Psychosomatic Med. 2008; 70:338-344.

Sullivan MD, Edlund MJ, Fan MY, Devries A, Brennan Braden J, Martin BC. Trends in use of opioids for non-cancer pain conditions 2000-2005 in commercial and Medicaid insurance plans: The TROUP study. Pain. 2008; 138:440-449. [PubMed: 18547726]

Sullivan MD, Edlund MJ, Fan MY, Devries A, Brennan Braden J, Martin BC. Risks for possible and probable opioid misuse among recipients of chronic opioid therapy in commercial and medicaid insurance plans: The TROUP Study. Pain. 2010; 150:332-339. [PubMed: 20554392]

Sullivan MD, Edlund MJ, Zhang L, Unutzer J, Wells KB. Association between mental health disorders, problem drug use, and regular prescription opioid use. Arch. Intern. Med. 2006; 166:2087-2093. [PubMed: 17060538]

Tassain V, Attal N, Fletcher D, Brasseur L, Dégieux P, Chauvin M, Bouhassira D. Long term effects of oral sustained release morphine on neuropsychological performance in patients with chronic non-cancer pain. Pain. 2003; 104:389-400. [PubMed: 12855350]

Thayer JF, Lane RD. Claude Bernard and the heart-brain connection: further elaboration of a model of neurovisceral integration. Neurosci. Biobehav. Rev. 2009; 33:81-88. [PubMed: 18771686]

Tiffany ST. A cognitive model of drug urges and drug-use behavior: role of automatic and nonautomatic processes. Psychol. Rev. 1990; 97:147-68. [PubMed: 2186423]

Tousignant-Laflamme Y, Marchand S. Sex differences in cardiac and autonomic response to clinical and experimental pain in LBP patients. Eur. J. Pain. 2006; 10:603-614. [PubMed: 16298532]

Tracey I. Getting the pain you expect: mechanisms of placebo, nocebo and reappraisal effects in humans. Nature Med. 2010; 16:1277-1283. [PubMed: 20948533]

Tracey I, Mantyh PW. The cerebral signature for pain perception and its modulation. Neuron. 2007; 55:377-391. [PubMed: 17678852]

Traynor JR, Wood MS. Distribution of opioid binding sites in spinal cord. Neuropeptides. 1987; 10:313-320. [PubMed: 2829051]

Trescot AM, Datta S, Lee M, Hansen H. Opioid pharmacology. Pain Physician. 2008; 11:S133-153. [PubMed: 18443637]

Turk DC, Swanson KS, Gatchel RJ. Predicting opioid misuse by chronic pain patients: A systematic review and literature synthesis. Clin. J. Pain. 2008; 24:497-508. [PubMed: 18574359] 
Turner JA, Jensen MP, Warms CA, Cardenas DD. Catastrophizing is associated with pain intensity, psychological distress, and pain-related disability among individuals with chronic pain after spinal cord injury. Pain. 2002; 98:127-134. [PubMed: 12098624]

Vago DR, Nakamura Y. Increased selective attention towards pain-related threat in fibromyalgia: Preliminary evidence for effects of mindfulness meditation training. Cog. Ther. Res. 2011; 35:581-594.

Vago DR, Silbersweig DA. Self-awareness, self-regulation, and self-transcendence S-ART : A framework for understanding the neurobiological mechanisms of mindfulness. Front. Hum. Neurosci. 2012; 6:1-30. [PubMed: 22279433]

Verdejo A, Toribio I, Orozco C, Puente KL, Pérez-García M. Neuropsychological functioning in methadone maintenance patients versus abstinent heroin abusers. Drug Alcohol Depend. 2005; 78:283-288. [PubMed: 15893159]

Vogt BA. Pain and emotion interactions in subregions of the cingulate gyrus. Nat. Rev. Neurosci. 2005; 6:533-544. [PubMed: 15995724]

Volkow ND, Wang G-J, Fowler JS, Tomasi D, Telang F. Addiction: Beyond dopamine reward circuitry. PNAS. 2011; 108:15037-15042. [PubMed: 21402948]

Voscopoulos C, Lema M. When does acute pain become chronic? Br. J. Anaesthesia. 2010; 105:i69i85.

Waddell G. Low back pain: a twentieth century health care enigma. Spine. 1996; 21:2820. [PubMed: 9112705]

Waddell G, McCulloch J, Kummel E, Venner RM. Nonorganic physical signs in low-back pain. Spine. 1980; 5:117-125. [PubMed: 6446157]

Wagner KJ, Sprenger T, Kochs EF, Töolle TR, Valet M, Willoch F. Imaging human cerebral pain modulation by dose-dependent opioid analgesia: a positron emission tomography activation study using remifentanil. Anesthesiology. 2007; 106:548-556. [PubMed: 17325514]

Walker DJ, Zacny JP. Subjective, psychomotor, and physiological effects of cumulative doses of opioid $\mu$ agonists in healthy volunteers. J. Pharm. Exp. Ther. 1999; 289:1454-1464.

Wanigasekera V, Lee MC, Rogers R, Kong Y, Leknes S, Andersson J, et al. Baseline reward circuitry activity and trait reward responsiveness predict expression of opioid analgesia in healthy subjects. PNAS. 2012; 109:17705-17710. [PubMed: 23045652]

Wasan AD, Loggia ML, Chen LQ, Napadow V, Kong J, Gollub RL. Neural correlates of chronic low back pain measured by arterial spin labeling. Anesthesiol. 2011; 115:364-374.

Wasan AD, Ross EL, Michna E, Chibnik L, Greenfield SF, Weiss RD, Jamison RN. Craving of prescription opioids in patients with chronic pain: A longitudinal outcomes trial. J. Pain. 2012; 13(2):146-154. [PubMed: 22245713]

Weisenberg M, Raz T, Hener T. The influence of film-induced mood on pain perception. Pain. 1998; 76:365-375. [PubMed: 9718255]

Wenk-Sormaz H. Meditation can reduce habitual responding. Altern. Ther. Health Med. 2005; 11:4258. [PubMed: 15819448]

Westbrook C, Creswell JD, Tabibnia G, Julson E, Kober H, Tindle HA. Mindful attention reduces neural and self-reported cue-induced craving in smokers. Soc. Cog. Affect. Neurosci. 2011

Witkiewitz K, Bowen S. Depression, craving, and substance use following a randomized trial of mindfulness-based relapse prevention. J Consult. Clin. Psychol. 2011; 78:362-74. [PubMed: 20515211]

Wiech K, Tracey I. The influence of negative emotions on pain: behavioral effects and neural mechanisms. Neuroimage. 2009; 47:987-94. [PubMed: 19481610]

Wilson JF. Strategies to stop abuse of prescribed opioid drugs. Ann. Intern. Med. 2007; 146:897-900. [PubMed: 17577013]

Wise RG, Rogers R, Painter D, Bantick S, Ploghaus A, Williams P, Rapeport G, Tracey I. Combining fMRI with a pharmacokinetic model to determine which brain areas activated by painful stimulation are specifically modulated by remifentanil. Neuroimage. 2002; 16:999-1014. [PubMed: 12202088]

Wood W, Neal DT. A new look at habits and the habit-goal interface. Psychol. Rev. 2007; 114:843863. [PubMed: 17907866] 
Yaksh TL. Spinal opiate analgesia: characteristics and principles of action. Pain. 1981; 11:293-346. [PubMed: 6276842]

Yaksh TL. Opioid receptor systems and the endorphins: a review of their spinal organization. J. Neurosurg. 1987; 67:157-176. [PubMed: 3037042]

Yin HH, Knowlton BJ. The role of the basal ganglia in habit formation. Nat. Rev. Neurosci. 2006; 7:464-476. [PubMed: 16715055]

Yücel M, Lubman DI, Harrison BJ, Fornito A, Allen NB, Wellard RM, Clarke K, Wood SJ, Forman $\mathrm{SD}$, Pantelis C. A combined spectroscopic and functional MRI investigation of the dorsal anterior cingulate region in opiate addiction. Mol. Psychiatry. 2007; 12:691-702.

Zacny JP, Bigelow G, Compton P, Foley K, Iguchi M, Sannerud C. College on Problems of Drug Dependence taskforce on prescription opioid non-medical use and abuse: position statement. Drug Alcohol Depend. 2003; 69:215-232. [PubMed: 12633908]

Zacny JP. A review of the effects of opioids on psychomotor and cognitive functioning in humans. Exp. Clin. Psychopharm. 1995; 3:432-466.

Zeidan F, Coghill RC. Functional connections between self-referential thought and chronic pain: A dysfunctional relationship. Pain. 2012 Advanced online publication. doi: 10.1016/j.pain. 2012.09.014.

Zeidan F, Grant JA, Brown CA, McHaffie JG, Coghill RC. Mindfulness meditation-related pain relief: Evidence for unique brain mechanisms in the regulation of pain. Neurosci. Lett. 2012; 520:165173. [PubMed: 22487846]

Zeidan F, Martucci KT, Kraft RA, Gordon NS, McHaffie JG, Coghill RC. Brain mechanisms supporting the modulation of pain by mindfulness meditation. J. Neurosci. 2011; 31:5540-5548. [PubMed: 21471390]

Zelman DC, Howland EW, Nichols SN, Cleeland CS. The effects of induced mood on laboratory pain. Pain. 1991; 46:105-111. [PubMed: 1896201]

Zillman D, de Wied M, King-Jablonski C, Jenzowsky S. Drama-induced affect and pain sensitivity. Psychosomatic Med. 1996; 58:333-341. 


\section{Highlights}

Prescription opioid misuse among chronic pain patients is a public health threat. Cognitive-affective factors interact with the neuropharmacology of opioid analgesia.

Opioid misuse may arise out of dysfunctional brain connectivity and allostasis.

We describe a conceptual model linking chronic pain and addictive opioid use.

Our model has implications for mindfulness-based treatment of these comorbidities. 


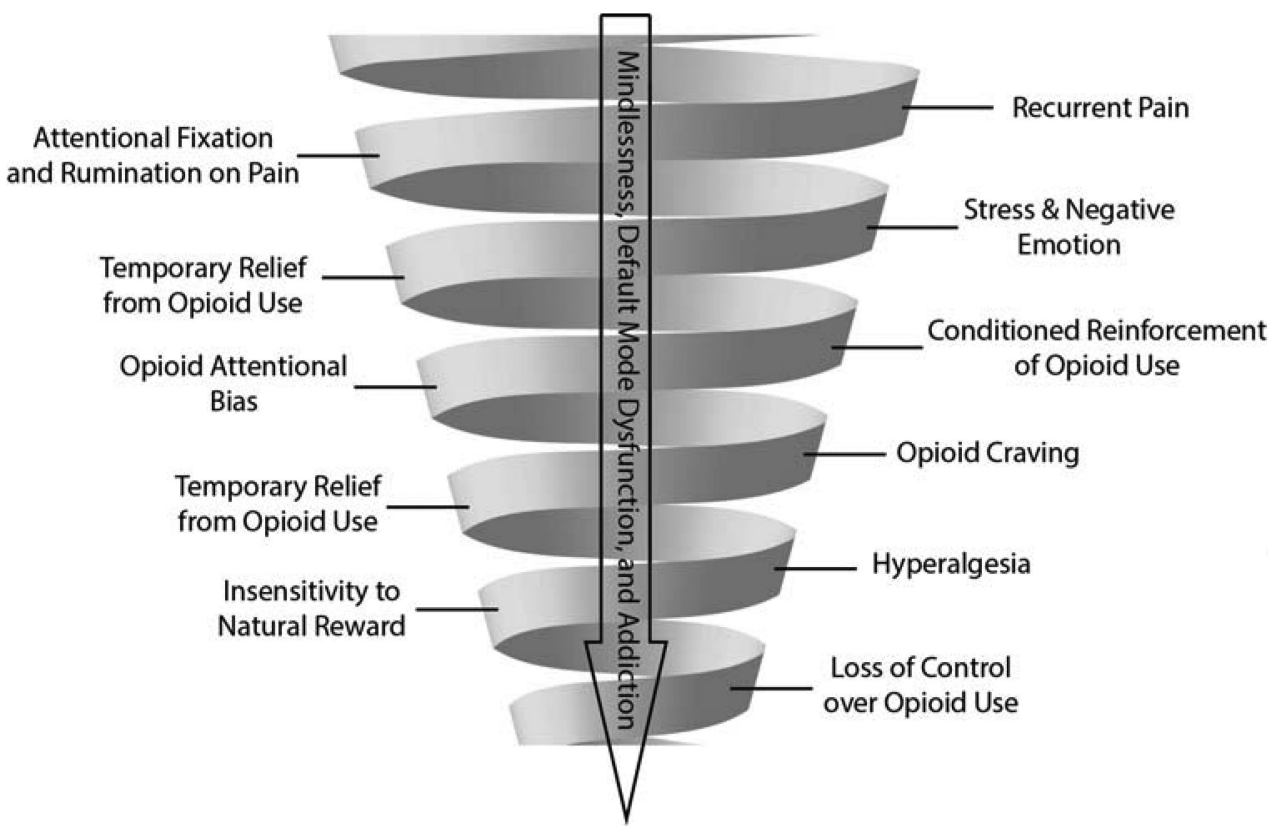

Figure 1.

The Downward Spiral of Chronic Pain and Opioid Addiction.

In brief, the problem of co-occurring chronic pain and opioid addiction involves a cycle of behavioral escalation in which nociception triggers pain hypervigilance and catastrophizing, amplifying pain with emotional anguish. Among affectively dysregulated individuals, recurrent self-administration of opioids in response to pain and negative emotions results in associative learning processes that bias attention towards opioid-related cues (e.g., a sight of a pill bottle), strengthening the automatic habit of opioid use despite tolerance to opioid analgesia. Chronic pain and prolonged opioid misuse causes allostatic changes to stress and reward circuitry in the brain, increasing sensitivity to pain and decreasing the pleasure derived from healthful objects and events. As functional connectivity between the default mode network and other neural circuits changes over time, the sense of self may become entwined with pain-laden narratives and entrapped by a compulsive drive for relief. This downward spiral may ultimately result in mindless, uncontrolled opioid use and addiction. 